\title{
Enseñanza del Cálculo Diferencial e Integral y Análisis de Errores: Contribuciones a los procesos de enseñanza y aprendizaje
}

\author{
Carmen Teresa Kaiber ${ }^{1}$ \\ carmen_kaiber@hotmail.com \\ https://orcid.org/0000-0003-1883-230X
}

Priscila Augusta de Quadros Scott Hood ${ }^{1}$

prihood@gmail.com

https://orcid.org/0000-0002-9496-397X

${ }^{1}$ Universidade Luterana do Brasil (ULBRA)

Canoas, Brasil

Recibido: 07/05/2020 Aceptado: 22/05/2020

\begin{abstract}
Resumen
Este artículo presenta análisis, discusiones y reflexiones sobre el potencial del análisis de errores en la identificación de dificultades presentadas por los estudiantes de Cálculo Diferencial e Integral como una forma de organización y planificación favorables al trabajo en esta área del conocimiento, considerando los datos que surgieron de la investigación titulada "Cálculo Diferencial e integral: una propuesta de monitoreo en linea en el Facebook". La investigación cualitativa se basó en aspectos teóricos sobre la naturaleza de las dificultades en el aprendizaje del Cálculo e hipótesis del análisis de errores. Los datos se tomaron tomándose en cuenta la producción de los estudiantes al realizar una prueba de Cálculo y se los analizaron con un protocolo creado considerando construcciones propias de la investigación en el análisis de errores. Con respecto a las posibles dificultades en el aprendizaje, observadas a partir del análisis realizado, destacamos aquellas que están vinculadas a aspectos conceptuales relacionados con la resolución de derivadas por definición por límite, así como a procedimientos relacionados con conceptos y propiedades elementales dentro del ámbito de Matemáticas. Finalmente, se destacan aspectos de un proyecto desarrollado que considere los errores y dificultades identificados, como posibilidad de articulación de un trabajo estructurado basado en ellos.

Palabras clave: Aprendizaje de Cálculo Diferencial e Integral. Análisis de Errores, Errores en el Cálculo de Derivadas.

\section{O Ensino do Cálculo Diferencial e Integral e a Análise de Erros: contribuições para os processos de ensino e aprendizagem}

\section{Resumo}

Este artigo apresenta análises, discussões e reflexões sobre potencialidades da análise de erros na identificação de dificuldades apresentadas por estudantes de Cálculo Diferencial e Integral como caminho para a organização e planejamento favoráveis ao trabalho nessa área de conhecimento, considerando dados que emergiram da investigação intitulada "Cálculo Diferencial e Integral: uma proposta de monitoria online no Facebook". A investigação, de base qualitativa, fundamentou-se em aspectos teóricos sobre a natureza de dificuldades no estudo do Cálculo e pressupostos da análise de erros. Os dados foram tomados considerando a produção de estudantes ao realizarem uma prova de Cálculo e foram analisados com protocolo criado considerando constructos próprios da pesquisa em análise de erros. No que se refere as 
potenciais dificuldades na aprendizagem, observadas a partir da análise realizada, destaca-se as que estão atreladas a aspectos conceituais referentes a resolução de derivada pela definição por limite, bem como a procedimentos relacionados a conceitos e propriedades elementares no âmbito da Matemática. Por fim, se coloca em destaque aspectos de um projeto desenvolvido considerando os erros e dificuldades identificados, como possibilidade de articulação de um trabalho estruturado a partir dos mesmos.

Palavras chave: Aprendizagem do Cálculo Diferencial e Integral, Análise de Erros, Erros no Cálculo de Derivadas.

\title{
The Teaching of Differential and Integral Calculus and the Analysis of Errors: Contributions to the Teaching and Learning Processes
}

\begin{abstract}
This article presents analyses, discussions and reflections on the potential of error analysis to identify students' difficulties in Differential and Integral Calculus as a form of organization and planning that are favourable to work in this area of knowledge, considering data that emerged from the investigation entitled "Cálculo Diferencial e Integral: uma proposta de monitoria online no Facebook" (Differential and integral calculus: a proposal for online tutoring on Facebook). The qualitative research was based on theoretical aspects on the nature of difficulties in calculus and assumptions of error analysis. The data were collected considering the students' production when doing a Calculus examination and were analyzed with a protocol created considering constructs proper to the research in error analysis. Regarding the potential difficulties in learning observed from the analysis carried out, we highlight those that are bound to conceptual aspects related to the resolution of derivative by the limit definition, as well as procedures related to elementary concepts and properties within the scope of mathematics. Finally, we highlight aspects of a project developed considering the errors and difficulties identified, as a possibility of articulation of a structured work based on them.
\end{abstract}

Keywords: Differential and Integral Calculus Learning, Error Analysis, Errors in Derivative Calculation.

\section{Introdução}

O Cálculo Diferencial e Integral é uma área de conhecimento que se ocupa da análise de fenômenos quantificáveis que envolvam uma relação funcional entre grandezas, sejam elas físicas ou matemáticas, as quais podem ser descritas por meio de palavras, dados numéricos, gráficos e modelos matemáticos (Anton, 2006). Possui caráter integrador, articulando uma série de conceitos advindos de outras áreas da Matemática, tais como aritmética, álgebra e geometria, na busca pela solução de problemas fundamentais das mais diversas áreas do conhecimento científico humano que tratam de questões relacionadas às ideias de variabilidade e movimento (Rezende, 2003).

Seu estudo se faz presente em diferentes cursos do ensino superior da área científica e tecnológica e demanda dos estudantes o domínio de conhecimentos matemáticos abordados 
desde a educação básica, em especial no Ensino Médio. Em tais cursos, o tratamento dado aos objetos matemáticos no âmbito de um componente curricular voltado ao estudo do Cálculo Diferencial e Integral possui caráter formal, buscando atingir um nível de rigor mais profundo, para o qual nem sempre os estudantes que ingressam em cursos superiores estão preparados (Barufi, 1999). Enquanto que, em nível médio, por exemplo, os estudantes precisam trabalhar com noções básicas sobre funções, identificando e representando modelos funcionais, aplicando tais modelos em situações-problema elementares, ao estudarem Cálculo, é necessário aprofundar essa noção e os modelos funcionais em um grau de rigor maior, aplicando-os na solução de problemas nem sempre triviais, utilizando diferentes conhecimentos e procedimentos matemáticos, os quais nem sempre foram bem desenvolvidos em sua formação na educação básica.

Investigações apontam que o aprofundamento no trabalho com o Cálculo leva os estudantes a apresentarem dificuldades no andamento de seus estudos (Artigue, 1995; Barufi, 1999; Cury, 2008; Rezende, 2003, Reis, 2001). No contexto educacional brasileiro, tais dificuldades têm conduzido os estudantes a apresentarem baixo rendimento o que, segundo Oliveira e Raad (2012), contribui para o fortalecimento de uma cultura escolar de reprovação, na qual altos índices de retenção em componentes curriculares voltados ao estudo do Cálculo são vistos com normalidade por estudantes e, até mesmo, por professores.

Nesse contexto, se considera pertinente e importante investigações que busquem identificar e analisar a natureza e ordem das dificuldades apresentadas, na busca de elementos os quais permitam intervir nos processos de ensino e aprendizagem estabelecendo condições e ambientes favoráveis ao desenvolvimento dos estudantes. Particularmente, destacam-se no presente artigo discussões e reflexões sobre o potencial da identificação e análise de erros apresentados por acadêmicos ao estudarem Cálculo, com vistas a encontrar caminhos e práticas que os instrumentalizem para o enfrentamento das dificuldades que venham a se apresentar. Nesse sentido, pesquisadores como Bisognin, Fioreze e Cury (2007), Cury (2008), Cury, Bisognin E. e Bisognin V. (2009), Cury e Cassol (2004), Del Puerto, Minnaard e Seminara (2006), Movshovitz-Hadar, Zaslavsky e Inbar (1987), Pereira Filho, Kaiber e Lélis (2012) têm realizado investigações na área, os quais buscam aprofundar as discussões a partir de realidades locais. 
Os argumentos e justificativas apresentados deram suporte ao desenvolvimento de uma pesquisa que teve como objetivo investigar a utilização do Facebook na constituição e implementação de uma proposta de monitoria online de Cálculo Diferencial e Integral de funções de uma variável, em uma Universidade privada da Região Metropolitana de Porto Alegre/RS, Brasil, adotando suportes teóricos referentes à análise de erros para a identificação de erros recorrentes cometidos pelos acadêmicos com vistas a estabelecer estratégias para um trabalho de apoio aos mesmos. O desenvolvimento e resultados dessa investigação encontramse em Scott Hood (2018) e Scott Hood e Kaiber (2017a, 2017b, 2018a, 2018b).

Assim, no âmbito da investigação produzida, apresentam-se aqui, discussões e reflexões sobre as potencialidades da análise de erros na identificação de dificuldades apresentadas por estudantes de Cálculo como caminho para a organização e planejamento favoráveis ao trabalho com a disciplina. Tais discussões e reflexões são encaminhadas a partir de uma análise realizada em um conjunto de provas de estudantes de Cálculo de uma instituição particular de Ensino Superior, local onde a investigação foi conduzida. Foi tomando como aporte teórico as naturezas das dificuldades encontradas no estudo do Cálculo Diferencial e Integral, segundo literatura em parte já destacada, e protocolo da análise de erros com base em Movshovitz-Hadar, Zaslavsky e Inbar (1987).

No que segue, apresenta-se uma discussão sobre aspectos da natureza das dificuldades encontradas no estudo do Cálculo, bem como de pressupostos teóricos da Análise de Erros.

\section{Dificuldades no Estudo do Cálculo Diferencial e Integral}

Oliveira e Raad (2012) apontam que são muitos os pesquisadores que, ao longo das últimas décadas, desenvolveram investigações relacionadas aos processos de ensino e aprendizagem do Cálculo Diferencial e Integral, como já apresentado. Destacam que parte significativa desses trabalhos se relaciona com as dificuldades de aprendizagem enfrentadas por estudantes em diferentes níveis de ensino, buscando identificar se as causas de tais dificuldades são de natureza didática ou epistemológica, embora se considere que as mesmas estão relacionadas, tal como destacado por Rezende (2003).

Barufi (1999) pondera que as diferentes perspectivas de ensino adotadas pelos professores de Cálculo se enquadram entre dois paradigmas de abordagem: o histórico e o lógico-formal. Segundo a autora, um ensino organizado a partir de uma abordagem histórica 
considera a ordem cronológica de desenvolvimento dos conceitos, buscando apresentá-los a partir de problematizações que remetam ao contexto histórico no qual tais conceitos foram concebidos. Por outro lado, destaca que em uma abordagem baseada no padrão lógico-formal, a ordem de apresentação dos conceitos se baseia em uma sequência que preza por uma lógica interna sem, necessariamente, considerar o processo histórico. No Quadro 1 é dado destaque como a autora entende que o ensino de Cálculo se organiza considerando as mencionadas abordagens.

Quadro 1: Paradigmas de abordagem do Cálculo Diferencial e Integral

\begin{tabular}{|c|c|}
\hline ABORDAGEM HISTÓRICA & $\begin{array}{l}\text { ABORDAGEM LÓGICO- } \\
\text { FORMAL }\end{array}$ \\
\hline $\begin{array}{l}\text { 1. Integração através de problemas envolvendo área } \\
\text { (quadratura), volume (cubatura), comprimento de } \\
\text { arco (retificação). }\end{array}$ & 1.Os números reais. \\
\hline $\begin{array}{l}\text { 2. Diferenciação através de problemas de tangentes, } \\
\text { valores extremos, normais e curvatura. }\end{array}$ & 2. Funções elementares. \\
\hline $\begin{array}{l}\text { 3. Unificação do Cálculo Integral e do Cálculo } \\
\text { Diferencial por meio do Teorema Fundamental do } \\
\text { Cálculo. }\end{array}$ & 3. Limites. \\
\hline 4. Equações Diferenciais Ordinárias. & 4. Diferenciação. \\
\hline 5. Desenvolvimento de notações e símbolos. & $\begin{array}{l}\text { 5. Estudo detalhado de funções de } \\
\text { uma variável. }\end{array}$ \\
\hline 6. Conceito de função. & 6. Integração. \\
\hline $\begin{array}{l}\text { 7. O conceito de quantidades infinitamente pequenas, } \\
\text { indivisíveis e quantidades divisíveis ad infinitum. }\end{array}$ & $\begin{array}{l}\text { 7. Teorema Fundamental do } \\
\text { Cálculo. }\end{array}$ \\
\hline $\begin{array}{l}\text { 8. O abandono eventual dos infinitésimos e a } \\
\text { determinação do conceito de limite como conceito } \\
\text { fundamental do Cálculo. }\end{array}$ & $\begin{array}{l}\text { 8. Equações } \\
\text { Ordinárias. }\end{array}$ \\
\hline 9. Os números reais. & - \\
\hline
\end{tabular}

Fonte: Adaptado de Barufi (1999, pp. 158-159).

Em suas pesquisas, considerando a análise de um conjunto de 17 livros de Cálculo Diferencial e Integral, a autora identificou uma acentuada predominância do padrão lógicoformal, sendo a abordagem histórica presente em somente duas das obras analisadas. Embora predominante, o padrão lógico-formal é criticado pela autora, uma vez que, segundo ela, essa abordagem transforma o trabalho realizado ao longo de mais de vinte séculos por pensadores, filósofos e matemáticos em um tipo de tratamento metodológico que “[...] obedece, em muitos casos, à ideia de fornecer uma revelação do Cálculo. A proposta parece basear-se no fato questionável de que a lógica interna consistente deva garantir a aprendizagem significativa por parte dos estudantes" (Barufi, 1999, p. 52, grifo da autora). Pondera que, apesar de a estrutura 
lógico-formal visar um rigor formal mais profundo, muitas vezes, faz com que os objetos do Cálculo adquiram pouco significado para os estudantes, tendo em vista que, para muitos deles, “[...] o conhecimento matemático, desenvolvido anteriormente, na escola secundária, pouco ou nada tem a ver com o que lhe é apresentado no curso de Cálculo, e o caráter de análise com o que passa a se defrontar parece constituir uma grande dificuldade" (Barufi, 1999, p, 5). Destaca, ainda, que uma abordagem pautada no modelo histórico possui um potencial mais elevado para problematizações, pois simula as demandas a partir das quais foram formulados os conceitos que culminaram no Cálculo Diferencial e Integral, destacando que tal processo não ocorreu de forma linear, conforme faz parecer a abordagem lógico-formal.

A realidade brasileira, no que se refere ao ensino do Cálculo, está fortemente relacionada a abordagem lógico-formal apresentada pela autora, o que é apontado por Reis (2001) como uma das causas das dificuldades de aprendizagem que os estudantes apresentam. Porém, Rezende (2003) pondera que, apesar do ensino do Cálculo estar organizado a partir de uma lógica que, de certa maneira, fere o caminho epistemológico-histórico, as relações estabelecidas nessa perspectiva de ensino trazem, tanto colaborações à sistematização dos conhecimentos matemáticos constituídos pelos alunos, como a rigorização de como o conhecimento pode ser transposto ao aluno.

Artigue (1995), em uma perspectiva que se entende envolve aspectos epistemológicos, cognitivos e didáticos, destaca que a natureza das dificuldades enfrentadas pelos estudantes na aprendizagem do Cálculo são diversas, agrupando-as em três grandes categorias: dificuldades associadas com à complexidade dos objetos básicos do Cálculo; dificuldades associadas à conceituação e à formalização da noção de limite; dificuldades vinculadas às rupturas necessárias em relação aos modos de pensamento puramente algébricos e às especificidades do trabalho técnico realizado no Cálculo. Uma descrição das mencionadas categorias é apresentada no Quadro 2. 
Quadro 2: Dificuldades relacionadas à aprendizagem do Cálculo Diferencial e Integral

CATEGORIA
Dificuldades
associadas com
os objetos
básicos do
Cálculo.

Dificuldades associadas à conceituação e a formalização da noção de limite.

\section{DESCRIÇÃO}

Agrega dificuldades relacionadas à mudança de tratamento dado a objetos tais como os números reais e as funções, tendo em vista que os mesmos são trabalhados ao longo da Educação Básica como objetos em construção, sendo formalizados no Ensino Superior. No que se refere ao conceito de funções, são destacadas quatro subcategorias:

- dificuldades apresentadas pelos estudantes em identificar, de fato, o que é uma função;

- dificuldades envolvendo o reconhecimento da dualidade das funções enquanto processo e entidade conceitual;

- dificuldades cognitivas envolvendo a articulação entre diferentes registros simbólicos, além dos hábitos de ensino que superestimam os registros algébricos frente aos geométricos;

- dificuldades relacionadas ao uso das funções como ferramentas matemáticas. Refere-se ao entendimento de que a noção de limites ocupa lugar de destaque em investigações voltadas ao ensino do Cálculo, dado seu caráter essencial para a constituição dos demais conceitos, sendo destacadas as seguintes dificuldades:

- significação equivocada do termo limite, na qual o mesmo é entendido como uma barreira intransponível e inalcançável, como se fosse uma marca ou o último termo do processo;

- dificuldades relacionadas ao tratamento algébrico atribuído à noção de limites quando a mesma se refere a ideia de continuidade, de modo que são aplicadas noções de propriedades comuns, sem que o estudante compreenda de que forma isso se insere no contexto mais global da sua aplicação;

- dificuldades resultantes de falsas generalizações ocorridas a partir de um tratamento geométrico dado à noção de limites, no qual são reforçadas concepções errôneas tais como a ideia de que se um objeto tende geometricamente a outro, os limites das suas magnitudes associadas tenderão às magnitudes do objeto limite;

- a autora cita, também, dificuldades relacionadas ao duplo status da noção de limites: o operacional e o estrutural. Nesse caso, há certa dificuldade em analisar o limite por um viés que não seja puramente procedimental, dando foco ao objeto limite que o constituiu e analisando seu real significado;

- por fim, dificuldades relacionadas à formalização padrão da noção de limite. Embora a formalização padrão da noção de limites funcione como um todo indivisível, é comum que os estudantes a tratem como dois processos distintos: um associado a variável e outro aos valores da função.

Dificuldades associadas à ruptura entre Álgebra e Cálculo.
Agrega dificuldades relacionadas aos diferentes tratamentos dados aos objetos matemáticos por áreas como o Cálculo e a Álgebra. Como exemplo, destaca-se a noção de igualdade:

No campo da Álgebra, busca-se transformar uma igualdade do tipo $a(x)=b(x)$ em uma sucessão de procedimentos $a_{i}(x)=b_{i}(x)$ até que se obtenham expressões em que a igualdade é uma afirmação verdadeira. Já no Cálculo, a análise pode ser realizada a partir do comparativo entre duas funções, como por exemplo, as funções $f(x)$ e $g(x)$, cujos contradomínios são definidos no conjunto dos números reais, tal que para todo ponto do contradomínio a imagem de $f(x)$ é menor ou igual a de $g(x)$. A necessidade nesse tipo de expressão está em avaliar para quais pontos do contradomínio a igualdade é verdadeira.

Fonte: Adaptado de Artigue (1995). 
Ao se voltar para aspectos específicos os quais envolvem diretamente os objetos de estudo do Cálculo, a autora permite uma análise mais específica das possíveis dificuldades enfrentadas pelos estudantes, que podem ser relacionadas diretamente à ação dos professores.

Nessa mesma linha de pensamento, Rezende (2003) considerando questões de natureza epistemológica destaca cinco dualidades que se manifestam no tratamento dos objetos do Cálculo e que se apresentam como possíveis dificuldades: discreto/contínuo, variabilidade/permanência, finito/infinito, local/global e sistematização/construção, as quais articulam, também, aspectos históricos e pedagógicos.

De acordo com o autor, a dualidade discreto/contínuo "[...] se constitui pelas discussões em torno do problema histórico e fundamental da medida de grandezas geométricas, intuitivamente contínuas, através de processos aritméticos discretos” (Rezende, 2003, p. 327). Pondera, ainda, que historicamente, tais dificuldades se originam de questões relativas à incomensurabilidade de determinados segmentos geométricos, as quais persistiram até a formalização do conjunto dos números reais, mas especificamente a concepção do conjunto dos números irracionais.

No âmbito pedagógico, Rezende (2003) ponta que a dualidade discreto/contínuo é ignorada em diversos níveis do ensino da Matemática, não sendo um problema restrito aos cursos de Cálculo. Porém, no estudo do Cálculo Diferencial e Integral, esse aspecto se evidencia pelo uso indiscriminado do Teorema Fundamental do Cálculo e das técnicas de integração em detrimento da integral de Riemann e das noções referentes ao estudo de séries, atrelado, ainda, ao conhecimento limitado dos estudantes em relação aos conjuntos numéricos. De acordo com o autor esse conhecimento se restringe ao conjunto dos números racionais, enquanto que, em relação aos irracionais, se limitam ao uso de técnicas operatórias.

A dualidade variabilidade/permanência, por sua vez, ocupa-se de questões referentes à relação de interdependência entre quantidades variáveis, mais especificamente à taxa de variação de uma das variáveis em relação à outra (Rezende, 2003). Conforme apontado pelo autor, as dificuldades associadas a essa dualidade expressam um entendimento puramente estático em relação ao conceito de função por parte dos alunos ingressantes no ensino superior, no qual a função se resumiria a expressão analítica que a define, sendo desconsiderada a relação funcional que ela representa. Nesse sentido, pondera que o esboço e o estudo dos gráficos das diferentes funções se dão por meio da aplicação de uma tabela restrita de valores para $x$ à 
expressão que representa a função, de modo que sua representação gráfica se constitui de um processo estático, estético e induzido por propriedades algébricas.

No que se refere à dualidade de finito/infinito, o autor aponta para a questão de que no Cálculo, e mesmo na própria Matemática, a noção de infinito se apresenta como um dos elementos primordiais para a elaboração do que conecta os conceitos discreto/contínuo. Tal conexão está assentada, principalmente, nas ideias trabalhadas no conjunto dos números reais, como os conceitos de função e da aproximação para calcular a área de uma região. Segundo o autor, inicialmente, o conceito de infinito pode ser elementar de ser compreendido partir de potenciais tentativas de relacioná-lo com ideias daquilo que é "incontável", "sem fim", "ilimitado" (Rezende, 2003). Pondera que a complexidade desse conceito se mostra, geralmente, no estudo de elementos matemáticos que abordam questões relacionadas a incomensurabilidade ou não-enumerabilidade e a própria noção de convergência de um dado limite.

Rezende (2003) destaca que, a partir de uma perspectiva pedagógica, a noção de limites, no âmbito do Cálculo, é um dos conceitos matemáticos dos quais o aluno tenta expressar seu entendimento sobre infinito. Considera que, muitas vezes, as resoluções, entendimentos e explicações dos alunos estão atreladas apenas a um ponto de vista algébrico, nem sempre verdadeiro, como, por exemplo, ao diferenciar os tipos de infinito: onde existe o infinito "positivo" ou "negativo" para representar a tendência dos limites laterais de uma função em um dado ponto e o limite "sem sinal" que aponta para a não existência do limite. Para o autor, essa ideia trivial passa longe da significação que gira em torno daquilo é que é discreto/contínuo e que, no caso, se distancia das relações teóricas fundamentais da real interpretação que envolve o conceito matemático abordado.

No que se refere a dualidade local/global, essa está intimamente relacionada com temas como: "colagem de modelos locais em objetos globais, passagem local ao global e análise de suas obstruções e métodos de análise das estruturas locais e/ou globais não triviais, etc." (Rezende, 2003, p. 373). Tal entendimento é apontado pelo autor como um importante elemento para trazer significado ao produto da percepção humana sobre local e global, destacando-o como um potencial ampliador de interpretações sobre os elementos e abordagens da Geometria Euclidiana. Essa perspectiva, de acordo com o autor, aponta para as essenciais contribuições que o Cálculo teve com base nos conhecimentos da Geometria, apontando, dentre tantas, a possibilidade de relação e estudo com o Cálculo a partir da Geometria Analítica. 
Na perspectiva pedagógica dessa dualidade, Rezende (2003) considera que uma das grandes dificuldades no que se refere ao Cálculo está no entendimento sobre como os estudantes veem os conhecimentos matemáticos que são abordados. O autor pondera que a percepção de estudantes de Cálculo, pode ficar distorcida no ponto de vista do entendimento matemático, pois, por exemplo, simplificam conceitos complexos e profundos àquilo que enxergam em um dado problema. Essa visão dos estudantes pode trazer dificuldades na compreensão de abordagens mais amplas de como conceitos, como por exemplo derivadas, podem estar relacionados a determinadas situações-problema. $\mathrm{O}$ autor considera que a ação dos estudantes pode ficar limitada a uma percepção que não condiz com todas as potencialidades de utilização do referido conceito e, assim, concebe uma visão particular (local) de um conjunto de possibilidades mais gerais (global). Porém, destaca que o oposto também pode apresentar complexidades à abordagem dos conhecimentos do Cálculo, pois uma abordagem global pode trazer dificuldades ao estudante em como percebê-las em situações específicas que exijam sua aplicação.

Por fim, Rezende (2003) apresenta a dualidade sistematização/construção, que discute a forma como os conhecimentos são organizados ou sistematizados. Segundo o autor, as áreas de conhecimento da Matemática se organizam e se estruturam, inicialmente, em áreas mais abrangentes que, posteriormente, sistematizam todos os conhecimentos matemáticos, considerando, ainda, que essa sistematização na área do ensino do Cálculo, parte de pressuposto de sistematizações pedagógicas.

Rezende (2003) considera que, historicamente a emergência de alguns conhecimentos do Cálculo, como integral e derivada, ocorreram de forma distinta a como são concebidos no ensino de Cálculo atualmente. De acordo como o autor, as primeiras noções de integral surgem juntamente com conceitos relacionado ao estudo do cálculo de áreas e continuidade de regiões e, posteriormente, os conceitos relacionados ao estudo de derivadas. Porém, pondera que, no sentido pedagógico, apesar da ordem cronológica da constituição e formulação desses conceitos matemáticos, os atuais ensinos de Cálculo estão estruturados numa perspectiva sequencial de Cauchy-Weierstrass, que considera a lógica sistemática de ensino de Cálculo em: Limites, Continuidade, Derivadas e Integrais. Destaca, ainda, que num contexto mais amplo, o trabalho com o Cálculo, geralmente, pressupõe uma tática sistemática para seu ensino que considera a ordem: (1) revisões sobre os conhecimentos matemáticos que precedem o Cálculo (funções, 
álgebra e operações), (2) a sequência Cauchy-Weierstrass e (3) técnicas e exercícios de fixação (Rezende, 2003).

Segundo o autor, a essa sistematização de ensino estão vinculadas muitas das dificuldades que, epistemologicamente, o Cálculo conduz diante da construção e configuração dos conceitos matemáticos. Porém, pondera que tal sistematização parece trazer potenciais facilidades em como o ensino do professor de Cálculo pode ser conduzido e em como a aprendizagem do aluno toma forma diante do referido estudo.

Os apontamentos apresentados, junto a outros, estão nos fundamentos da investigação produzida, como caminho teórico tanto para o entendimento como para a análise das relações que se estabelecem nos processos de ensino e aprendizagem do Cálculo. Porém, atentando para a discussão em foco no presente artigo, argumenta-se que uma das formas de manifestação observável de possíveis dificuldades de aprendizagem dos estudantes, seja em Cálculo ou em outras disciplinas, é por meio do conhecimento dos erros que emergem e se revelam nas produções realizadas por eles. Nesse sentido, destaca-se a análise de erros como instrumento que possibilita a utilização dos erros cometidos pelos estudantes como elemento constituinte dos processos de ensino e aprendizagem, a qual é abordada na próxima seção.

\section{Análise de Erros}

Rico (1995) pondera que o erro é um objeto constante no processo de aprendizagem dos estudantes, no entanto, sendo o objetivo a aprendizagem correta dos conceitos, por muito tempo, sua presença foi tratada como uma evidência de fracasso no alcance de tal objetivo, de modo que se buscava, simplesmente, eliminá-lo. Essa visão foi sendo modificada com o passar do tempo, à medida que o erro se tornou objeto de estudo da Educação Matemática, e passou a passou a ser considerado a partir de outras perspectivas.

Nessa mesma linha de pensamento, Del Puerto, Minnaard e Seminara (2006), apontam que os erros estão presentes, constantemente, nas produções dos estudantes, sendo ocasionados

por dificuldades de diversas naturezas, geradas ao longo do processo de aprendizagem, as quais se conectam e reforçam em redes complexas que obstaculizam a aprendizagem, manifestandose na forma de respostas equivocadas. Concordando-se com os autores, considera-se que a análise dos erros promove uma valiosa informação sobre a construção do conhecimento 
matemático dos estudantes, com potencial para contribuir nos processos de ensino e aprendizagem.

Segundo Cury, Bisognin E. e Bisognin V. (2009), a análise de erros cometidos pelos estudantes possui elementos comuns aos processos avaliativos presentes no cotidiano escolar, podendo partir de uma categorização da resolução apresentada como correta, parcialmente correta ou incorreta. No entanto, as autoras destacam que, diferentemente de uma correção de caráter avaliativo, a análise de erros não tem como objetivo a atribuição de nota ou conceito, mas sim o levantamento de dados que possam ser utilizados em um contexto investigativo ou, então, no planejamento de estratégias de ensino. Bisognin, Fioreze e Cury (2005) apontam, ainda, que "conhecer as concepções dos alunos sobre algum conceito, analisar como ele pensa ao resolver um problema são elementos que podem fazer da análise de erros uma forma de pesquisar a própria prática pedagógica” (p. 32).

Cury e Cassol (2004) destacam que a análise de erros, enquanto abordagem de pesquisa em Educação Matemática, originou-se nos Estados Unidos e na Europa, no início do século XX, assumindo, ao longo do tempo, diferentes enfoques dependendo dos pressupostos teóricos que amparavam as investigações e do nível de ensino ao qual se destinavam. Conforme indicado pelas autoras, as primeiras pesquisas realizadas eram voltadas à contagem dos erros ocorridos em exercícios padronizados e tinham como única finalidade a busca pela detecção e classificação dos erros cometidos pelos estudantes, sem explicitar teorias cognitivas ou pedagógicas que os justificassem, ficando implícitas as teorias do pesquisador em relação aos processos de ensino e aprendizagem (Cury, 2008; Cury; Cassol, 2004).

Em um segundo momento, de acordo com as autoras, as pesquisas passaram a incluir, além da contagem e classificação dos erros, uma busca por compreender suas causas, os obstáculos inerentes aos conteúdos analisados e sobre as concepções dos estudantes. Nesse contexto, Cury e Cassol (2004) ponderam que, embora os erros façam parte dos dados analisados em pesquisas que envolveram a análise de erros, esses deixaram de ser o foco e as pesquisas da área passaram a concentrar seus esforços em descobrir as motivações e causas desses erros. De acordo com as autoras, os princípios utilizados tiveram, com frequência, o uso de aportes piagetianos e vygotskianos, bem como o uso de ideias de autores franceses que trabalham a engenharia didática. 
Em um terceiro tipo de investigação emergente da análise de erros, Cury e Cassol (2004) destacam o surgimento de pesquisas que buscaram trazer atividades voltadas para estudantes e, com base na análise das resoluções e soluções de questões, os erros eram discutidos com base em referencial teórico que subsidiava a proposta investigativa. Esses tipos de propostas permitiram perceber abordagens para trabalhar a análise de erros, inclusive, enquanto proposta metodológica para o professor em sala de aula.

Concorda-se com Cury (2008), quando argumenta que a análise de erros, em uma perspectiva do ensino e da aprendizagem, permite ao professor compreender como os erros se apresentam nas resoluções dos alunos e que tipos de dificuldades ou obstáculos emergem desses. A autora destaca que investigar os erros dos alunos possibilita um entendimento, para o professor, sobre como os estudantes vem estruturando sua aprendizagem, com potencial para o entendimento de questões relativas a como os erros podem ser trabalhados com o objetivo de aprimorar o conhecimento.

É nessa perspectiva que a análise de erros é tomada na presente investigação: como uma ferramenta para a identificação e compreensão de erros, os quais possam vir a expressar potenciais dificuldades na aprendizagem de conceitos e procedimentos matemáticos por parte dos alunos de Cálculo. Esse entendimento, permite, dentre várias possibilidades, formas de se pensar sobre como os erros cometidos por estudantes podem ser utilizados no desenvolvimento de propostas de colaboração, com foco na redução das dificuldades de aprendizagem vivenciadas por esses alunos.

Cury (2008) destaca que existem diversas formas e modelos voltados à análise de erros, os quais são formulados a partir de diferentes concepções teóricas e metodológicas que se inserem nas investigações com alunos. Em suas pesquisas a autora destaca modelos teóricos sobre análise de erros, tanto publicados por autores brasileiros como por estrangeiros, os quais emergiram de investigações realizadas em diferentes níveis de ensino.

Dentre esses modelos teóricos de análise de erros destaca-se a perspectiva teórica de Movshovitz-Hadar, Zaslavsky e Inbar (1987), a qual será tomada na presente investigação. A motivação do uso deste modelo está no entendimento de que é possível constituir um instrumento investigativo para avaliar um quantitativo considerável de materiais, como registros de provas, trabalhos e produções de estudantes. 
Movshovitz-Hadar, Zaslavsky e Inbar (1987) constituíram um modelo de categorização que possibilitou generalizar erros cometidos por estudantes, considerando uma grande população de alunos. Segundo os autores, esse modelo foi criado a partir da análise de provas, com 18 questões abertas, de um exame anual aplicado com cerca de 20.000 estudantes do Ensino Médio durante dois anos seguidos e permitiu categorizar erros a partir de um conjunto de semelhanças e aproximações conceituais. O modelo definido pelos autores, a partir dessa investigação, é constituído por seis categorias, cada uma delas apresentando descritores que a caracterizam, os quais são apresentados a seguir:

No Quadro 3, destaca-se, de modo sucinto, a categorização elaborada pelos autores.

Quadro 3: Modelo para categorização de erros

\begin{tabular}{|l|l|}
\hline CATEGORIA & \multicolumn{1}{|c|}{ DESCRIÇÃo } \\
\hline $\begin{array}{l}\text { Uso incorreto } \\
\text { dos dados }\end{array}$ & $\begin{array}{l}\text { Esta categoria contempla casos envolvendo discrepância entre os dados } \\
\text { apresentados no problema e o tratamento dado a eles. Se refere as respostas nas quais } \\
\text { o estudante negligencia informações mencionadas, podendo suprir a falta de tais } \\
\text { informações por aspectos que não sejam pertinentes ao fenômeno estudado. }\end{array}$ \\
\hline $\begin{array}{l}\text { Linguagem } \\
\text { mal } \\
\text { interpretada }\end{array}$ & $\begin{array}{l}\text { Categoria na qual incluem-se erros que resultam da compreensão inadequada de } \\
\text { conceitos matemáticos. Esse tipo de situação se evidencia, por exemplo, em casos } \\
\text { nos quais o estudante traduz uma informação dada em linguagem natural em termo } \\
\text { matemático ou equação que não a representa ou, então, em casos nos quais símbolos } \\
\text { gráficos são interpretados como termos matemáticos e vice-versa. }\end{array}$ \\
\hline $\begin{array}{l}\text { Inferência } \\
\text { lógica } \\
\text { inválida }\end{array}$ & $\begin{array}{l}\text { Categoria destinada a erros que resultam de raciocínio falacioso decorrente de } \\
\text { inferências equivocadas, ocorridas ao longo do processo de resolução de uma } \\
\text { questão, sem necessariamente envolver um conteúdo específico. De acordo com as } \\
\text { autoras, nesse contexto, novas informações inválidas são elaboradas a partir de parte } \\
\text { de informações ou de informações inferidas anteriormente. }\end{array}$ \\
\hline $\begin{array}{l}\text { Teorema ou } \\
\text { definição } \\
\text { distorcida }\end{array}$ & $\begin{array}{l}\text { Essa categoria se refere as situações em que se apresentam erros relacionados a } \\
\text { forma como uma regra, teorema, definição ou princípio matemático foram } \\
\text { interpretados. Ainda, podem ser aqueles erros que emergem a partir de uma escrita } \\
\text { inadequada de um dado conceito matemático que foi utilizado ao longo de uma } \\
\text { resolução. }\end{array}$ \\
\hline $\begin{array}{l}\text { Solução não } \\
\text { verificada }\end{array}$ & $\begin{array}{l}\text { Situações de erros nas quais o aluno apresenta na resolução argumentações ou } \\
\text { justificativas corretas e relacionadas ao assunto, mas que, ao chegar na solução, } \\
\text { conclui algo que não responde o problema ou se mostra incorreto. }\end{array}$ \\
\hline Erro técnico & $\begin{array}{l}\text { Categoria de cunho instrumental que envolve erros em que o aluno não extrai } \\
\text { adequadamente as informações do problema ou aqueles que estão presentes em } \\
\text { operações procedimentais, como erros algébricos e aritméticos. }\end{array}$ \\
\hline
\end{tabular}

Fonte: Adaptado de Movshovitz-Hadar, Zaslavsky e Inbar (1987).

Movshovitz-Hadar, Zaslavsky e Inbar (1987) ponderam que, independente da visão teórica utilizada para analisar os erros cometidos, a emergência dos erros decorre de processos lógicos-matemáticos elaborados pelos estudantes ao longo de sua aprendizagem (MovshovitzHadar; Zaslavsky; Inbar, 1987), dos quais podem emergir interpretações que são consideradas adequadas ou não na perspectiva educacional. Além disso, embora esse modelo tenha sido 
constituído a partir de erros de estudantes do Ensino Médio, considera-se, com base em Pereira Filho, Kaiber e Lélis (2012), que tal perspectiva possa ser ampliada para estudos do nível superior, considerando-se, ainda, que erros ocorrem de modo transversal nos processos de ensino e aprendizagem de todos os níveis de ensino (Rico, 1995; Cury, 2008).

\section{Metodologia}

As análises, discussões e reflexões aqui apresentadas foram desenvolvidas tomando como referência uma pesquisa que teve por objetivo investigar a utilização do Facebook na constituição e implementação de uma proposta de uma monitoria online de Cálculo Diferencial e Integral de funções de uma variável. A investigação teve lugar em uma Universidade privada da Região Metropolitana de Porto Alegre/RS e foi desenvolvida junto a acadêmicos matriculados nas disciplinas de Cálculo I e II, que foram divididos em dois grupos: o primeiro contou com a participação de 222 acadêmicos, que disponibilizaram avaliações realizadas ao longo do segundo semestre de 2016, nas referidas disciplinas; o segundo, formado por 15 participantes, participou de uma proposta de monitoria online, que ocorreu, por adesão, no primeiro semestre de 2017. A pesquisa foi submetida ao Comitê de Ética em Pesquisa em Seres Humanos da Universidade Luterana do Brasil, tendo sido aprovada mediante protocolo CAAE de $n^{\text {o } 59961816.5 .0000 .5349 . ~}$

A investigação, de cunho qualitativo, em seu contexto mais amplo contou com a aplicação de questionários ao grupo participante, análise de questionamentos e das produções dos estudantes a partir da interação via Facebook. Porém, como suporte para a organização e implementação do projeto recorreu-se a análise de erros como caminho para se ter conhecimento, previamente, de possíveis dificuldades encontradas pelos estudantes no Cálculo Diferencial e Integral referente ao estudo de Funções, Limites, Derivadas e Integrais.

A busca pela literatura sobre dificuldades apresentadas por estudantes no trabalho com o Cálculo e sobre a análise de erros, abriu um universo de possibilidades de utilização de tal análise no sentido de contribuir ao processo de aprendizagem dos estudantes no âmbito local e como fundamento para o estabelecimento de estratégias para o aprofundamento de conhecimentos pertinentes, o que levou a um aprofundamento de tais análises.

Assim, tomou-se como objeto de análise questões oriundas de provas realizadas pelos acadêmicos no período, disciplinas e quantitativo já destacados. A análise envolveu a leitura de 
tais provas com a permissão de estudantes e professores, as quais foram fotocopiadas após a correção dos professores. Após sucessivas leituras quando foram descartadas questões que apresentavam erros similares ou não respondidas, foi estabelecido o conjunto de questões a serem analisadas.

No contexto da investigação, para a análise de erros, tomou-se como referência a categorização estabelecida por Movshovitz-Hadar, Zaslavsky e Inbar (1987), já apresentada, e que propõem, de maneira prévia seis categorias de análise: uso incorreto dos dados, linguagem mal interpretada, inferência lógica inválida, teorema ou definição distorcida, solução não verificada e erro técnico, já descritas em seção anterior.

No âmbito da investigação, a partir dos resultados obtidos na identificação, categorização e análise dos erros, o objetivo era associar potenciais dificuldades apresentadas em relação aos diferentes conceitos e procedimentos exigidos na avaliação, o que viria a servir como parâmetro para a seleção de material de apoio, entre os quais, vídeos disponíveis na plataforma YouTube, os quais trouxessem situações relacionadas aos erros e dificuldades identificados, para serem utilizados no contexto do projeto de monitoria proposto. No que segue são destacados aspectos da análise realizada.

\section{Apresentação e Análise dos Dados}

Serão apresentadas, nessa seção, análises e discussões acerca das produções de seis participantes da investigação, referentes à resolução de questão envolvendo o cálculo da derivada de uma função por meio da definição de derivada. Essa questão faz parte de uma avaliação aplicada em uma turma de Cálculo I, sendo que se teve acesso a avaliações de dezoito acadêmicos. Destaca-se que não se tem como intenção quantificar os erros encontrados no conjunto de provas analisadas, mas sim apontar erros que sejam relevantes para o entendimento das potenciais dificuldades enfrentadas pelos estudantes no trabalho com a derivada. No texto os participantes serão identificados por um código alfanumérico do tipo TxAy, no qual x indica o número da turma e y o número atribuído ao acadêmico.

Foram selecionadas para análise as produções de seis participantes - T3A1, T3A2, T3A3, T3A8, T3A11 e T3A12 - sendo apresentada, inicialmente, a do participante T3A11 (Figura 1), escolhida por apresentar resolução que se julgou adequada servindo como referência para a análise das demais, embora se tenha observações sobre a mesma. 
Figura 1: Resolução apresentada pelo participante T3A11

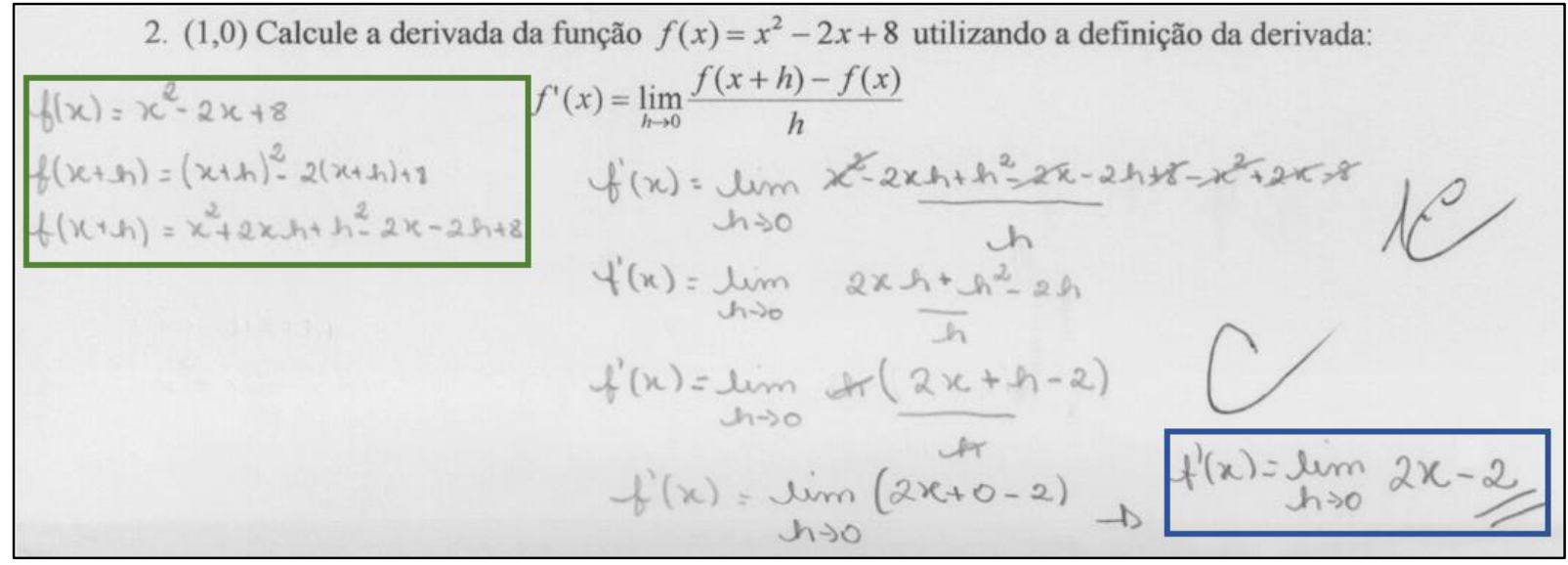

Fonte: a pesquisa.

Aponta-se, a partir dessa produção, que foi observado um padrão na resolução dos participantes (com exceção da que foi apresentada pelo T3A2), onde $f(x+h)$ é aplicado em $f(x)$, separadamente, para depois ser inserido na definição de derivada apresentada, tal como indicado do lado esquerdo da Figura 1. A observação desse procedimento em praticamente todo o conjunto de avaliações analisado, permitiu conjecturar tratar-se de um procedimento de resolução adotado no âmbito do desenvolvimento da disciplina, talvez com o propósito de evitar possíveis erros no desenvolvimento algébrico da questão. Outro aspecto observado refere-se ao fato que, ao final, como destacado na parte inferior direita da figura, a resposta final, ainda mantém a notação de limite, e não $f^{\prime}(x)=2 x-2$, como era de se esperar quando, por fim, se determinasse a derivada da função dada. Também, ao final, observa-se o cálculo do limite tomado como o cálculo do valor numérico de uma função, muito usual no trabalho com limites. Tais procedimentos surgem, juntos ou isoladamente nas produções que passam a ser analisadas.

No quadro da Figura 2, apresenta-se a produção do participante T3A8 exibida integralmente, sendo que os erros identificados serão destacados e analisados em seguida. 
Figura 2: Resolução apresentada pelo participante T3A8

2. $(1,0)$ Calcule a derivada da função $f(x)=x^{2}-2 x+8$ utilizando a definição da derivada:

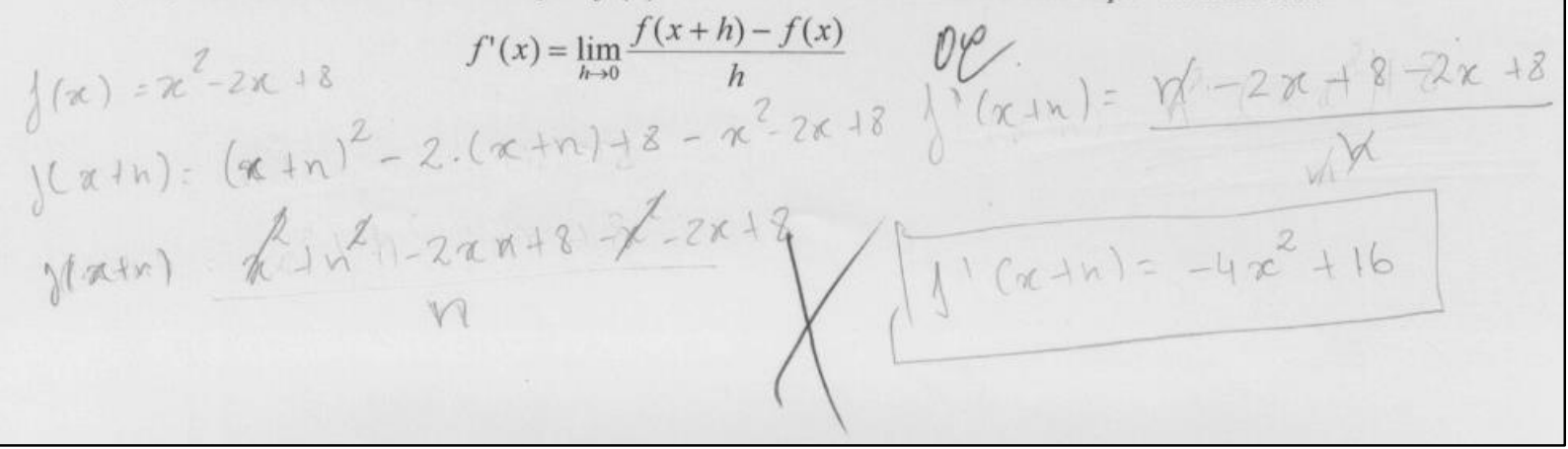

Fonte: a pesquisa.

Assim, apresenta-se no quadro da Figura 3 trechos da resolução do participante T3A8, juntamente com a descrição e análise dos erros identificados.

Figura 3: Erros cometidos pelo participante T3A8

\begin{tabular}{|c|c|c|c|}
\hline \multicolumn{3}{|r|}{ ERRO } & DESCRIÇÃO/ANÁLISE \\
\hline a) & $J(x+h)=$ & $\frac{(x+n)^{2}-2 \cdot(x+n)+8}{f(x+h)}-\frac{x^{2}-2 x+8}{f(x)}$ & $\begin{array}{l}\text { É indicado a realização do cálculo de } f(x+h) \text {, } \\
\text { porém o registro apresenta termos além dos que } \\
\text { são obtidos pela substituição do ponto }(x+h) \text { na } \\
\text { função dada no enunciado. Esses termos são } \\
\text { compatíveis com a função original, o que sugere } \\
\text { que o participante tenta subtrair } f(x) \text { de } f(x+h) \text {, } \\
\text { embora não tenha indicado tal intenção. }\end{array}$ \\
\hline b) & $y(x+h)=$ & $n$ & $\begin{array}{l}\text { Ao subtrair } f(x) \text { de } f(x+h) \text {, o participante não } \\
\text { faz uso de parênteses para indicar a necessidade } \\
\text { de realizar a operação distributiva do sinal } \\
\text { negativo que antecede } f(x) \text {, de modo que o } \\
\text { único termo que tem seu sinal alterado é } x^{2} \text {, } \\
\text { sendo mantidos os demais. }\end{array}$ \\
\hline c) & $\begin{array}{l}j(x+h)= \\
g(x+x)\end{array}$ & $(x+n)^{2}-2 \cdot(x+n)+8-x^{2}$ & $\begin{array}{l}\text { Além do erro já destacado nesse trecho da } \\
\text { resolução, aponta-se que o estudante não } \\
\text { desenvolveu o produto }(x+h)^{2} \text { corretamente, } \\
\text { resultando em } x^{2}+h^{2} \text {. Fica, assim, } \\
\text { caracterizado erro referente generalização de } \\
\text { propriedade da potência }(a . b)^{n}=a^{n} . b^{n} \text {, } \\
\text { traduzido pelo entendimento, pelo estudante, } \\
\text { que o quadrado de uma soma é a soma dos } \\
\text { quadrados, erro que, na literatura, é apontado } \\
\text { como recorrente (Rico, 1995), mas que para um } \\
\text { curso de Cálculo já poderia estar superado. } \\
\text { Ademais, identifica-se um erro referente a } \\
\text { aplicação da propriedade distributiva, pois } \\
-2 .(x+h) \text { resultou em }-2 x h .\end{array}$ \\
\hline
\end{tabular}

Continúa... 
Figura 3: Erros cometidos pelo participante T3A8 (continuação)

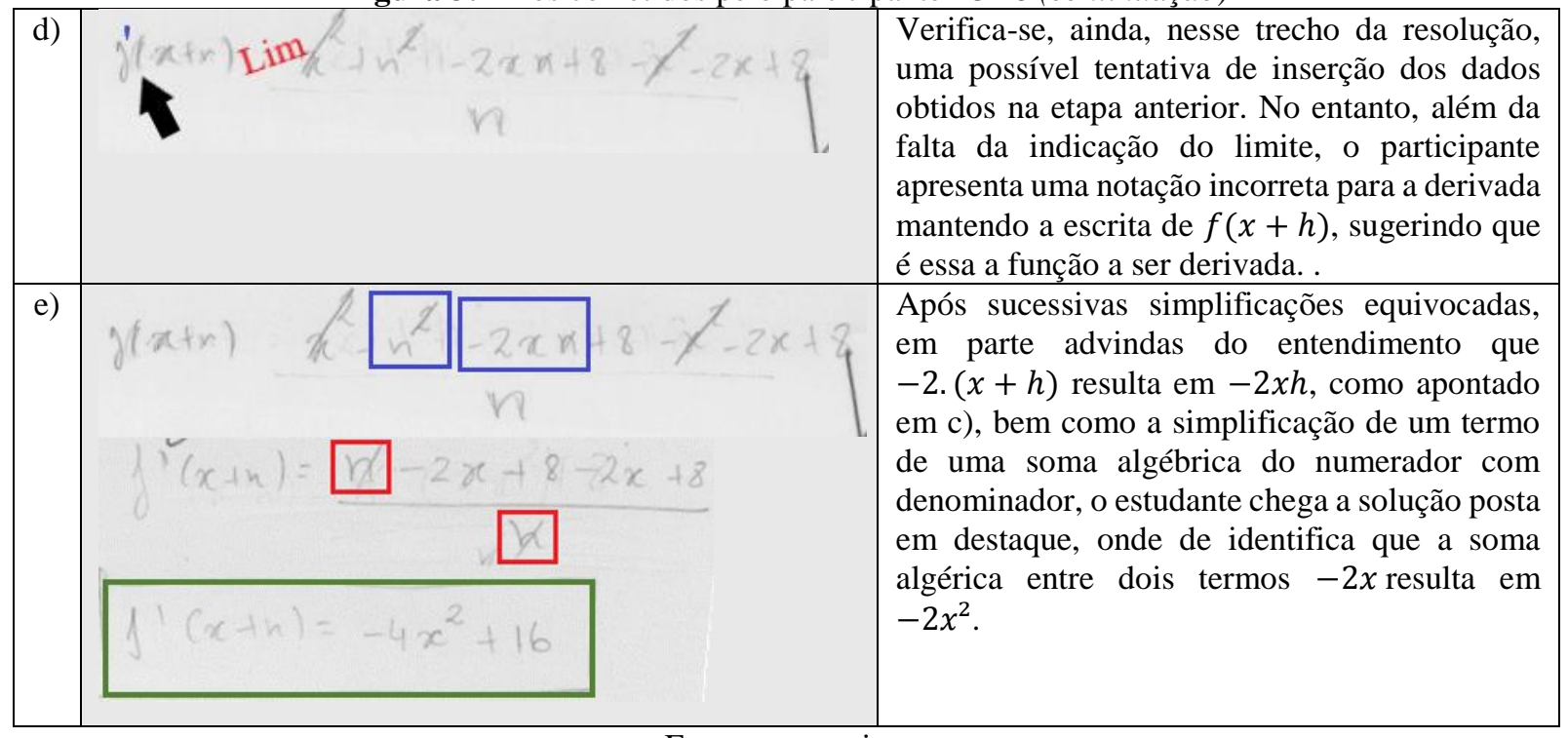

Fonte: a pesquisa.

Sobre essa questão entende-se que o pretendido, de fato, referia-se à aplicação adequada do procedimento do cálculo da derivada usando a definição, tal como proposto no enunciado. A questão e sua solução não se referem propriamente ao entendimento do significado dessa definição, mas sim a sua aplicação, o que deixa espaço para a identificação de conceitos e propriedades básicos que não são de domínio dos estudantes, mas que são basilares. Discute-se, porém, a pertinência de aplicação do procedimento adotado, onde $f(x+h)$ é aplicado em $f(x)$, separadamente, para depois ser inserido na definição de derivada. Pondera-se que, embora sua utilização remeta a busca por uma diminuição de possíveis erros técnicos de natureza algébrica, afasta o cálculo da derivada pela definição do entendimento do significado de uma derivada supostamente pretendido, aproximando-o de uma tarefa meramente procedimental.

Considerando-se o modelo para categorização de erros proposto por Movshovitz-Hadar, Zaslavsky e Inbar (1987), entende-se que os erros destacados podem ser considerados na categoria de teorema ou definição distorcida, o qual se refere a situações onde os erros estão relacionados a como uma definição, propriedade, teorema ou princípio matemático foram interpretados ou utilizados. No caso, observa-se a sucessiva utilização da propriedade distributiva e simplificações de forma incorreta, bem como o desenvolvimento do produto $(x+$ $h)^{2}$ considerando o emprego do que se entende como uma falsa generalização de uma das propriedades de potência.

Destaca-se, ainda, que erros que emergem de uma escrita inadequada de um dado conceito que foi utilizado na resolução também se encontram nessa categoria, o que pode ter 
ocorrido quando o estudante acrescenta o $-f(x)$ tal como está posto na primeira linha em a). Observa-se, porém, que esse erro se manteve na escrita do estudante na próxima linha.

Ainda no trecho da resolução apresentado em c), ao incluir o denominador $h$ nos dados que estava manipulando, o participante sugere que está fazendo uso da definição conforme solicitado na questão. No entanto, mesmo sendo informada a definição de derivada no enunciado, o participante a apresenta de forma incorreta, tal como mencionado na linha d). Considera-se que o erro referente ao uso de notação incorreta seja reflexo de um conhecimento não consolidado em relação proposto o que, por si só, se caracteriza como um caso de teorema ou definição distorcida (Movshovitz-Hadar; Zaslavsky; Inbar, 1987). No entanto, cabe destacar, segundo o modelo teórico adotado, que tais características aproximam esse erro, também, da categoria uso incorreto de dados, dada a discrepância entre os dados apresentados na questão e a resolução do participante, sendo negligenciadas partes da definição que estava posta.

Embora, isoladamente, erros cometidos na manipulação algébrica dos elementos envolvidos na derivada da função, estejam categorizados como erro técnico por MovshovitzHadar, Zaslavsky e Inbar (1987), o conjunto da solução apresentada aponta mesmo para erros referentes a diferentes conceitos e propriedades, não podendo ser caracterizados como erro técnico.

As próximas resoluções a serem analisadas são as dos participantes T3A1, T3A3 e T3A12. Por conterem erros pontuais, a análise será encaminhada de forma distinta da realizada na resolução do participante T3A8, de modo que o destaque dos erros será feito na própria imagem. Assim, apresenta-se na Figura 4 a resolução do participante T3A1, na qual verifica-se erro relacionado à notação da definição de derivada.

Figura 4: Resolução apresentada pelo participante T3A1

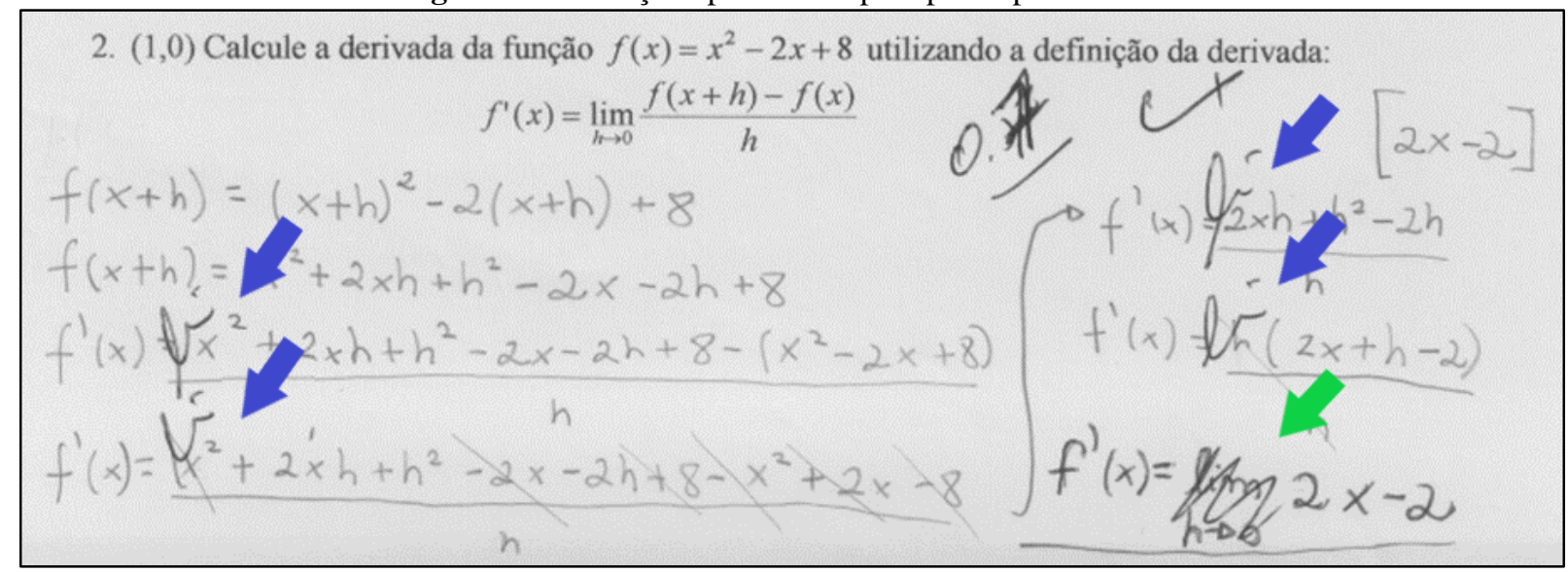

Fonte: a pesquisa. 
Verifica-se, com base no apresentado na Figura 4, que o participante inicia sua resolução aplicando $(x+h)$ na função $f(x)=x^{2}-2 x+8$, procedimento esse já destacado. Tal etapa é cumprida satisfatoriamente, no entanto, ao se voltar para a definição, a notação de limite não é considerada e o estudante passa a operar algebricamente com os termos envolvidos. Somente ao final, ao apresentar a derivada da função o limite surge, quando, na verdade, não deveria ser mais utilizado.

Entende-se que o erro cometido pelo participante possua um caráter conceitual, de modo que executa adequadamente as etapas algébricas da resolução, no entanto, essa execução revelase apenas procedimental. O cálculo da derivada pela definição tal como é apresentado, juntamente com sua representação geométrica, no contexto do desenvolvimento de seu estudo na disciplina de Cálculo, tem como pressuposto a aproximação do estudante com aspectos do desenvolvimento conceitual de derivada relacionado a declividade da reta tangente em determinado ponto de uma curva. Porém, ao dar um caráter puramente procedimental à solução, conjectura-se que o estudante ao utilizar $\lim _{h \rightarrow 0} \frac{f(x+h)-f(x)}{h}$ o toma somente como uma notação, não relacionado com o conceito em questão. Nesse sentido entende-se que o erro cometido pelo estudante T3A1 possa ser categorizado como teorema ou definição distorcida (MovshovitzHadar; Zaslavsky; Inbar, 1987), diretamente relacionado a conceitualização da derivada. Tal entendimento é reforçado por declarações dos estudantes que quando confrontados com a situação declaram que desenvolvem dessa forma porque é “mais fácil”, não vendo nenhum problema em resolver desse modo. Essa forma de resolução apresentada pelo participante T3A1 foi verificada, também, nas resoluções dos participantes T3A4, T3A6, T3A7, T3A13 e T3A17. Por fim, pondera-se que, mesmo estudantes que resolveram a questão de acordo com o padrão estabelecido, não necessariamente tenham se apropriado de aspectos conceituais que envolvem o trabalho com a derivada, considerando que o formato no qual a questão foi apresentada não permite emitir juízo de valor nessa direção.

No quadro da Figura 5 apresenta-se a resolução do participante T3A3, na qual verificamse erros envolvendo a resolução incorreta do produto notável dado por $(x+h)^{2}$ e à significação do limite envolvido na definição de derivada. 
Figura 5: Resolução apresentada pelo participante T3A3

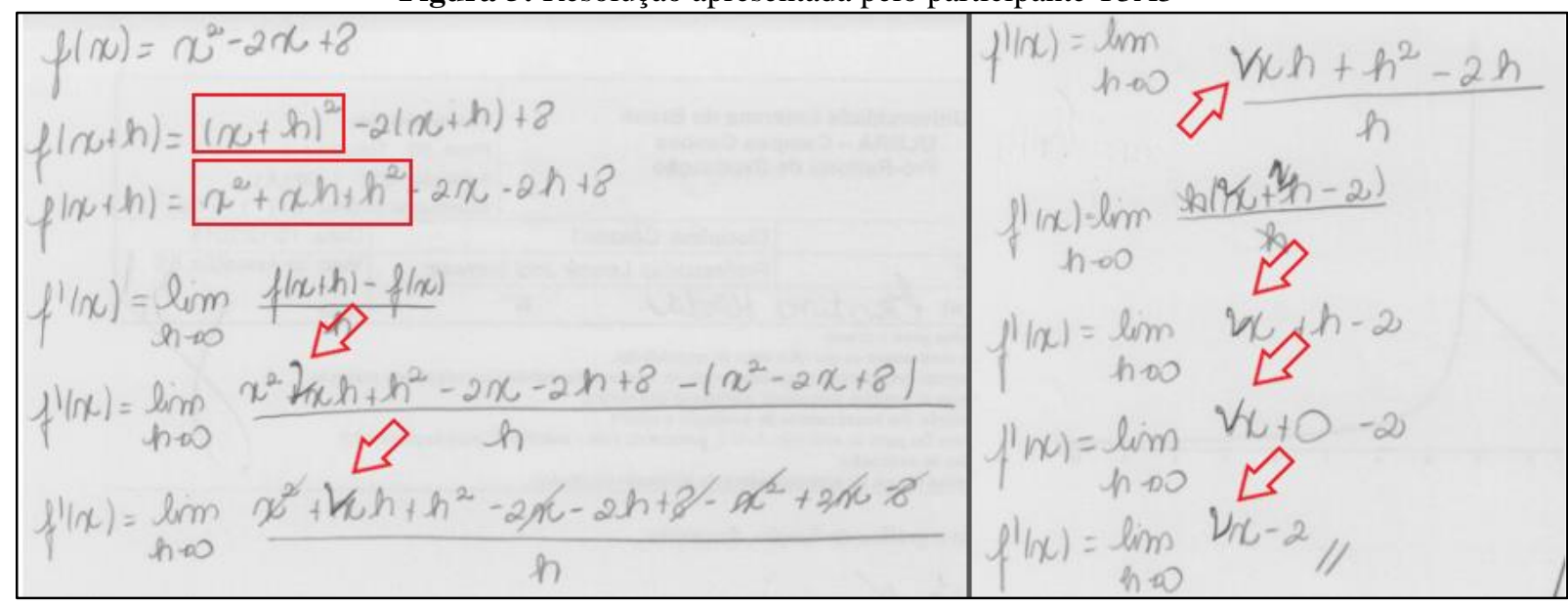

Fonte: a pesquisa.

Tal como realizado pelos participantes T3A11 e T3A8, o participante T3A3 inicia sua resolução aplicando o ponto $(x+h)$ na função dada no enunciado. No entanto, comete um erro ao calcular o produto notável dado por $(x+h)^{2}$, apontado como resultado $x^{2}+x h+h^{2}$ ao invés de $x^{2}+2 x h+h^{2}$, sendo que esse erro inicial estendeu-se a todo o desenvolvimento da questão. Observa-se que o erro cometido foi registrado pelo professor na correção, o que pode ser observado pela diferença de caligrafia e pelo destaque dado na figura.

Tal erro pode ser considerado como um caso de teorema ou definição distorcida (Movshovitz-Hadar; Zaslavsky; Inbar, 1987). Nesse caso, conjectura-se que o estudante aplicou o desenvolvimento do produto notável $(a+b)^{2}=a^{2}+2 a b+b^{2}$ considerando que de fato seu resultado é $a^{2}+a b+b^{2}$, o que poderia ter sido evitado se o mesmo desenvolvesse o produto ao invés de utilizar a regra, não se descartando, porém, a presença de um erro técnico.

Considerando-se o erro como técnico, entende-se que essa situação se aproxima, também, de um caso de solução não verificada da categorização de Movshovitz-Hadar, Zaslavsky e Inbar (1987), que ocorre em situações nas quais o aluno apresenta na resolução um desenvolvimento, argumentações ou justificativas corretas e relacionadas ao proposto mas, ao chegar na solução, conclui algo que não responde o problema ou se mostra incorreto.

Ainda em relação ao resultado, verifica-se que o participante mantém a escrita do limite tendendo a zero, mesmo após tendo aplicando na função obtida após a realização das simplificações algébricas realizadas. Esse erro sugere que o tratamento dado pelo participante à definição de derivada possui base procedimental, sem atribuir significado adequado ao limite e, consequentemente, à definição de derivada em si, tal como foi identificado em outras produções. 
Outro erro pontual a ser analisado é o apresentado pelo participante T3A12 e que pode ser visto no quadro da Figura 6.

Figura 6: Resolução apresentada pelo participante T3A12

2. $(1,0)$ Calcule a derivada da função $f(x)=x^{2}-2 x+8$ utilizando a definição da derivada:

$$
f^{\prime}(x)=\lim _{h \rightarrow 0} \frac{f(x+h)-f(x)}{h}
$$

$f(x+h)=(x+h)^{2}-2(x+h)+8$

$f(x+h)=x^{2}+2 x h+h^{2}-2 x-2 h+8$

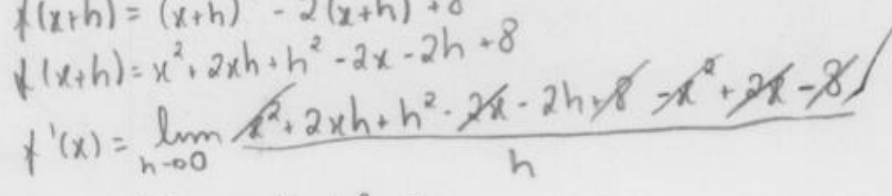

$f^{\prime}(x)=\lim _{x \rightarrow 0}$

$f^{\prime}(x)=2 x-2$

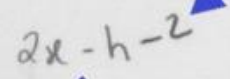

$f^{\prime}(x)=\lim _{h \rightarrow 0} \frac{2 x h+h^{2}-2 h}{h}$

$V^{\prime}(x)=\lim _{h \rightarrow 0} \frac{\not h(2 x+h-2 h)}{\not h}$

Fonte: a pesquisa.

Conforme indicado, verifica-se que o participante realiza processo de fatoração por evidência, entretanto mantém $h$ no último termo do numerador, obtendo $h \cdot(2 x+h-2 h)$ ao invés de $h .(2 x+h-2)$. Esse erro, aqui apontado como erro técnico, se propaga fazendo com que o resultado seja incorreto, o que é apontado pelo professor ao acrescentar ( -2 ) ao desenvolvimento final apresentado pelo estudante. Atrelado a esse erro técnico aponta-se a presença de um caso de solução não verificada da categorização de Movshovitz-Hadar, Zaslavsky e Inbar (1987) uma vez que o desenvolvimento apresentado foi adequado, porém, o que se considerou como erro técnico levou a um resultado incorreto.

Por fim, apresenta-se, na Figura 7, a resolução do participante T3A2, que se diferencia das demais pela forma como foi desenvolvida.

Figura 7: Resolução apresentada pelo participante T3A2

2. $(1,0)$ Calcule a derivada da função $f(x)=x^{2}-2 x+8$ utilizando a definição da derivada:

$$
f^{\prime}(x)=\lim _{h \rightarrow 0} \frac{f(x+h)-f(x)}{h}
$$

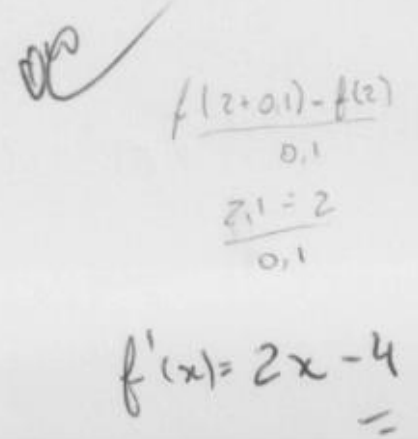

Fonte: a pesquisa. 
Verifica-se, com base no exposto, que o participante T3A2 não utiliza a definição posta na questão. Ao invés disso, atribui valores numéricos aleatórios para $x$ e $h$ (no caso 2 e 0,1 ), muito provavelmente oriundos de uma relação estabelecida com atividade realizada em aula, aplicando-os em $\frac{f(x+h)-f(x)}{h}$, não considerando a função dada. Por fim, indica um resultado que não se relaciona com os cálculos apresentados, o que se considera uma tentativa de aplicação de regra de derivação na função dada no enunciado, não se podendo identificar possível origem do termo $(-4)$ apresentado em $f^{\prime}(x)=2 x-4$. Assim, aponta-se para um caso de teorema ou definição distorcida relacionada ao uso incorreto de dados (Movshovitz-Hadar; Zaslavsky; Inbar, 1987), tendo em vista que o apresentado sugere falta de entendimento e domínio em relação ao cálculo de derivada pela definição e a utilização de dados e aplicação de técnicas de resolução alheias ao que é solicitado.

Para além da análise produzida com base categorização apresentada, foi possível perceber que a organização do trabalho no estudo do Cálculo, nas turmas envolvidas na investigação, considera a abordagem lógico-formal destacada em Barufi (1999), e em Rezende (2003) o que, via de regra, ocorre em praticamente todo o ensino superior brasileiro. Ademais, considerando os apontamentos de Artigue (1995), no que se refere às dificuldades enfrentadas por estudantes no estudo do Cálculo, a análise permitiu identificar elementos vinculados às três categorias apontadas pela autora: dificuldades associadas com a complexidade dos objetos básicos do Cálculo; dificuldades associadas à conceituação e a formalização da noção de limite; dificuldades vinculadas às rupturas necessárias em relação aos modos de pensamento puramente algébricos e às especificidades do trabalho técnico realizado.

Considerando as dificuldades associada com os objetos básicos do Cálculo, além das dificuldades associadas a tratamentos algébricos considerando conceitos e propriedades de matemática básica (propriedade distributiva e de potências, simplificação algébrica), foi possível identificar elementos indicativos de dificuldades com o tratamento dado a funções. Embora a questão fizesse referência ao cálculo de uma derivada, o domínio do objeto função é essencial para o entendimento do significado da derivada e do conceito de limite, o que envolve a categoria que destaca dificuldades com a noção e conceitualização de limite (Artigue, 1995). Tem-se o entendimento que estiveram presentes tanto dificuldades relacionadas ao reconhecimento da função enquanto entidade conceitual, bem como dificuldades envolvendo registros, particularmente no que se refere a limites. Ainda com relação a limites percebeu-se o 
que a autora se refere como significação equivocada do termo limite e seu entendimento enquanto entidade estrutural e não puramente procedimental, a ponto dos estudantes o utilizarem apenas como uma notação que pode ser agregada ao final do procedimento, ou tomado como a aplicação de um valor numérico em uma função, desprovido do seu significado enquanto objeto e na própria derivada.

Assim, com base na análise da produção dos estudantes, foi possível desenvolver um maior entendimento acerca das potenciais dificuldades enfrentadas por acadêmicos no trabalho com o Cálculo e, particularmente, considerando os exemplos destacados, na apropriação do desenvolvimento de derivadas no que se refere ao cálculo das mesmas pelo uso da definição, tal como apresentado. Destaca-se que, no âmbito das turmas foco da investigação, o objetivo do desenvolvimento desse tipo de atividade está relacionado a construção do significado da derivada a partir da aplicação geométrica do uso de limites para definir a tangente de uma curva, para, posteriormente, chegar ao conceito de derivada de uma função, embora se considere que a questão posta não abarca toda essa dimensão, não permitindo identificar os conhecimentos dos estudantes considerando esse aspecto. Todavia, é a questão que nas avaliações mais se aproxima desse objetivo, embora tenha um forte caráter procedimental.

Porém, o que se aponta como fundamental nesse processo é o conhecimento sobre os erros cometidos pelos estudantes, de modo que a partir destes o professor possa refletir sobre a aprendizagem dos estudantes e como seu próprio trabalho está sendo conduzido. No contexto da investigação, na qual está inserido as análises apresentadas nesse artigo, o conhecimento e entendimento dos erros e potencias dificuldades dos estudantes, serviu como base para a tomada de decisão em relação ao uso de materiais digitais, no contexto do projeto de monitoria proposto, voltados ao estudo dos conceitos abordados ao longo de um curso de Cálculo Diferencial e Integral. Foram selecionados vídeos online, disponíveis no YouTube, com diferentes formatos e abordagens, buscando oferecer aos participantes do projeto de monitoria online um material de apoio, particularmente direcionados para as dificuldades identificadas, que pudesse ser acessado a qualquer momento, inclusive em situações na qual a monitora não estivesse disponível. A seleção dos vídeos teve como critério a relação direta com as dificuldades observadas a partir da análise de erros realizada, a correção dos conceitos e a adequação didática coerente com materiais de referência institucional, como os livros didáticos indicados nos planos de ensino das disciplinas de Cálculo I e II. 
Para disponibilização desse material, foi utilizado, no Facebook, o espaço destinado aos álbuns de fotos, dada sua estrutura estável, que possibilitou a criação de álbuns, sendo cada um deles destinado aos seguintes conteúdos: Funções, Limites e Continuidade, Derivadas e Integras. Cada um desses álbuns continha uma série de fotos, que indicavam tópicos relacionados aos conceitos que denominavam os álbuns. Já os vídeos que se relacionavam a cada tópico, foram compartilhados, individualmente, no espaço destinado aos comentários das fotos, juntamente com uma descrição do vídeo. Buscava-se com essa estrutura, dar autonomia aos participantes, tendo em vista que potencialmente conheciam o ambiente virtual no qual foi realizada a monitoria, além da possibilidade do participante encontrar vídeo relacionado a potenciais dúvidas e dificuldades, com base na descrição do mesmo, sem a necessidade de investir tempo na seleção do material a ser utilizado.

No que se refere ao tópico de derivada pela definição de limites, foco da análise aqui apresentada, foram selecionados quatro vídeos, dos quais destaca-se o vídeo denominado "Derivada pela Definição por Limite", o qual foi produzido e disponibilizado pelo canal "Prof. Fabiano Meira"2. Esse canal conta, atualmente, com aproximadamente 26 mil inscritos e se destina a produção de conteúdo voltado ao estudo de conceitos relacionados à Física, Matemática e Engenharia.

Esse vídeo possui duração de pouco mais de sete minutos e se divide em três momentos: no primeiro, que dura aproximadamente 3:45 minutos, são apresentadas as etapas de derivação da função $f(x)=x^{2}+1$ por meio da definição de derivada; num segundo momento, cuja duração é de aproximadamente dois minutos, é utilizado software de geometria dinâmica para ilustrar as retas secante e tangente de uma curva genérica, mostrando como ambas se relacionam; por fim é apresentada a definição de derivada propriamente dita, relacionado a variação dos pontos envolvidos com os termos que a compõem. Os referidos trechos do vídeo são apresentados nas Figuras 8, 9 e 10.

\footnotetext{
${ }^{1}$ Disponível em https://youtu.be/D16AJQKdrhE Acesso em 12 abr 2020.

${ }^{2}$ Disponível em https://www.youtube.com/channel/UCCRSvj5Wj5bvcWNT2NuSp-A Acesso em 12 abr 2020.
} 
Figura 8: Cálculo da derivada por meio da definição

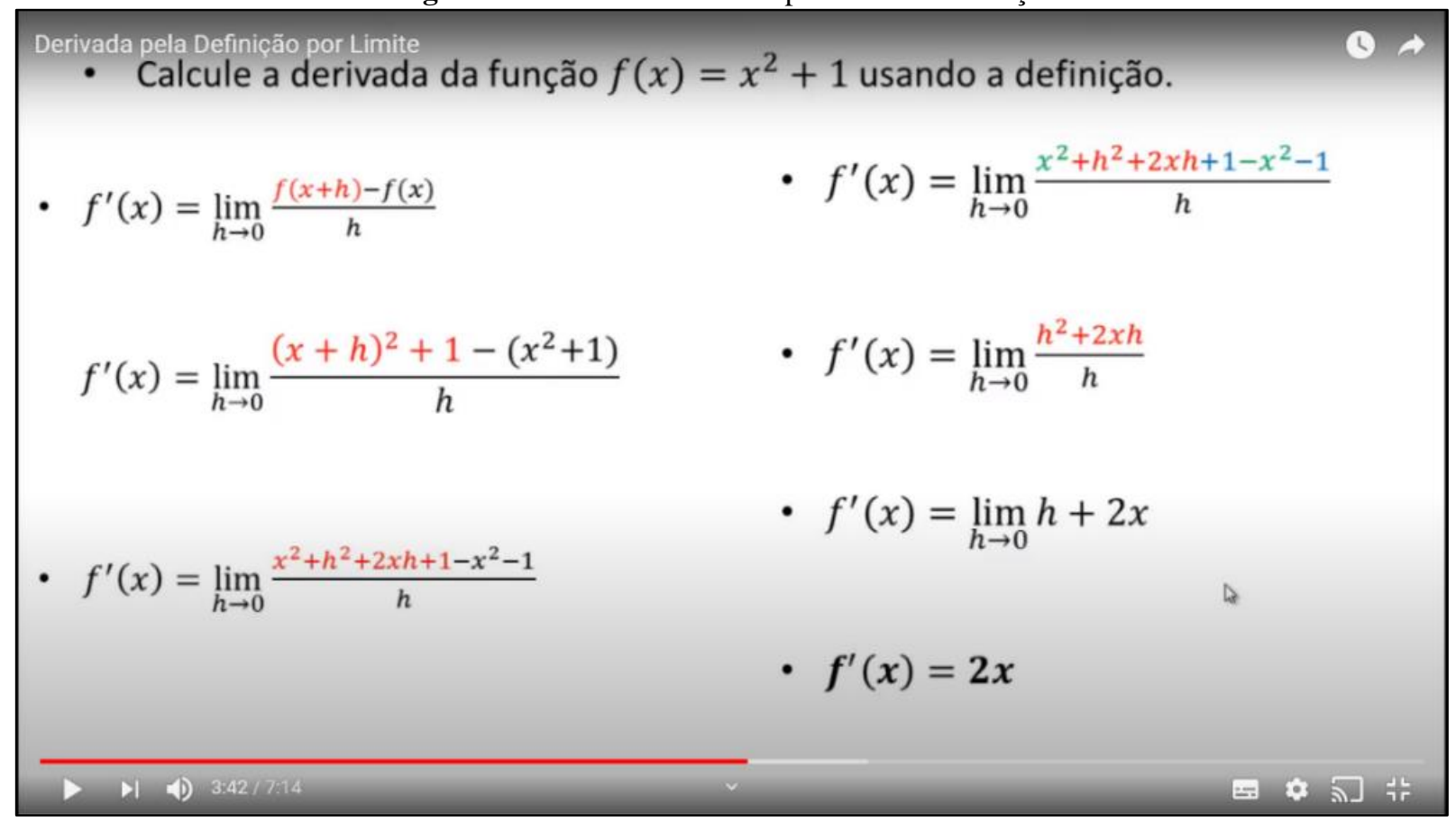

Fonte: Meira, F. [Canal Prof. Fabiano Meira]. Recuperado de https://youtu.be/D16AJQKdrhE

Conforme mencionado, nesse trecho do vídeo é apresentado o cálculo da derivada da função $f(x)=x^{2}+1$. Diferentemente do padrão observado nas resoluções analisadas, todo o processo é realizado na própria definição de derivada, sendo utilizadas diferentes cores para que possa ser percebida a relação entre cada etapa da resolução, o que também é narrado ao longo do vídeo. Considera-se que tais procedimentos vão ao encontro das potenciais dificuldades relacionadas aos erros que foram apontados previamente, tais como: a substituição do ponto $(x+h)$ na função a ser derivada e o desenvolvimento das operações algébricas envolvidas; 0 destaque para a operação distributiva relacionada à subtração de $f(x)$; as simplificações algébricas envolvidas entre as funções $f(x+h)$ e $f(x)$; a fatoração por evidência do termo $h$, a fim de simplificar o denominador; e, por fim, a aplicação do limite dos dados obtidos, determinando a derivada da função original.

No vídeo, ainda, é chamada a atenção para a necessidade de se colocar o procedimento de cálculo em sintonia com interpretações geométricas, o que leva ao segundo momento do vídeo, que se refere à representação gráfica das retas secante e tangente de uma função genérica, conforme indicado na Figura 9. 
Figura 9: Representação das retas secante e tangente de uma curva em relação à um determinado ponto

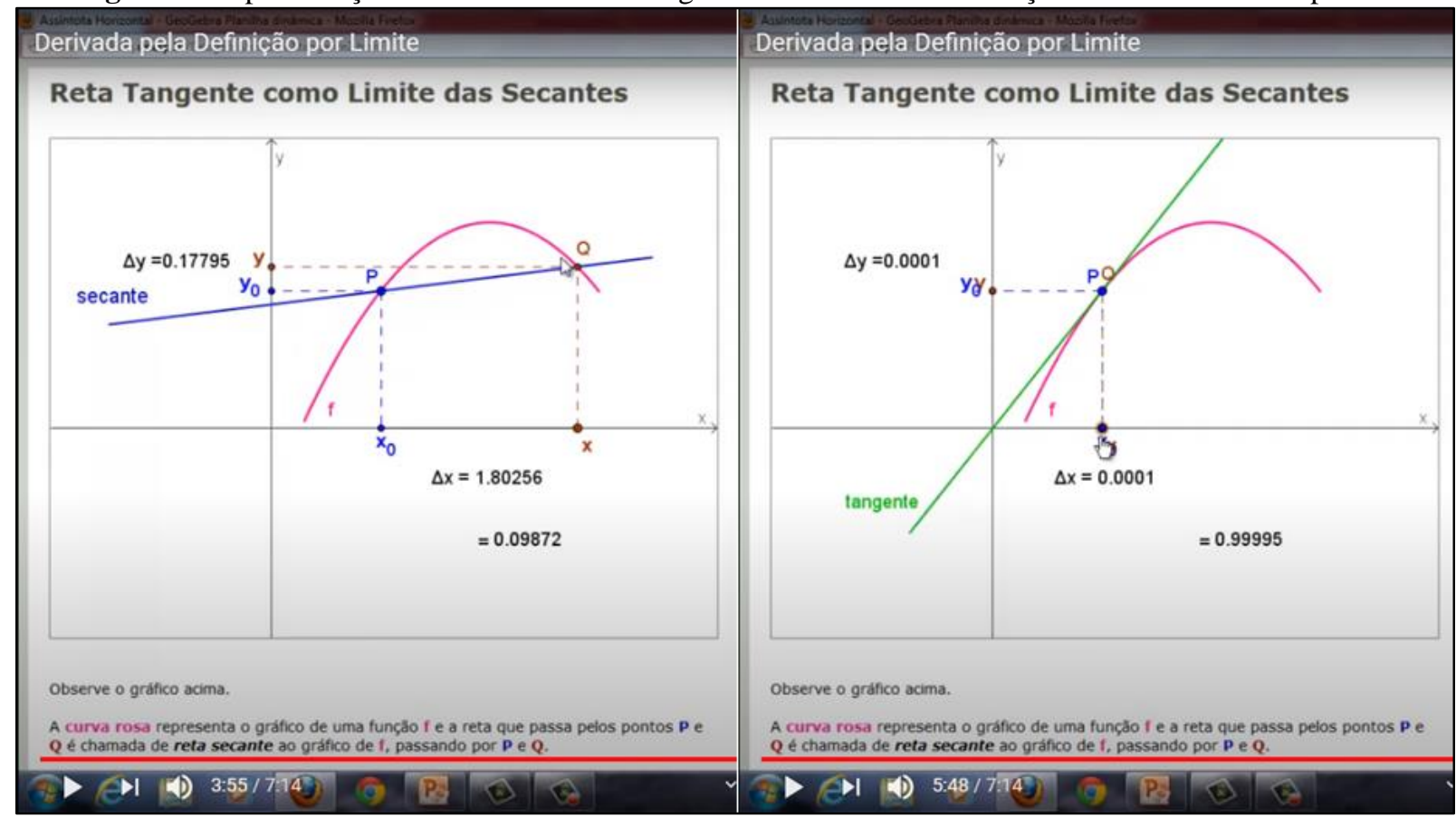

Fonte: Adaptado de Meira, F. [Canal Prof. Fabiano Meira]. Recuperado de https://youtu.be/D16AJQKdrhE

Utilizando software de geometria dinâmica é posto primeiramente, a representação de uma reta secante à uma curva genérica, destacando as variáveis dependente e independente que compõem as coordenadas dos pares ordenados referentes aos pontos $\mathrm{P}$ e Q, que são, justamente, onde a reta secante intercepta a curva. Logo após, variando a posição do ponto Q, aproximando sua variável independente cada vez mais da variável independente do ponto $\mathrm{P}$, altera-se, também, a distância entre esses dois pontos e, consequentemente, a inclinação da reta secante. É destacado que, à medida que a distância entre essas variáveis diminui, passando tender a zero, a distância entre os pontos $\mathrm{P}$ e Q torna-se progressivamente menor, de modo que a reta secante passa a tender a uma reta tangente. Dadas essas explicações, inicia-se o último trecho do vídeo, no qual a definição de derivada é relacionada a representação gráfica de uma reta secante (Figura $10)$. 
Figura 10: Representação gráfica da definição de derivad

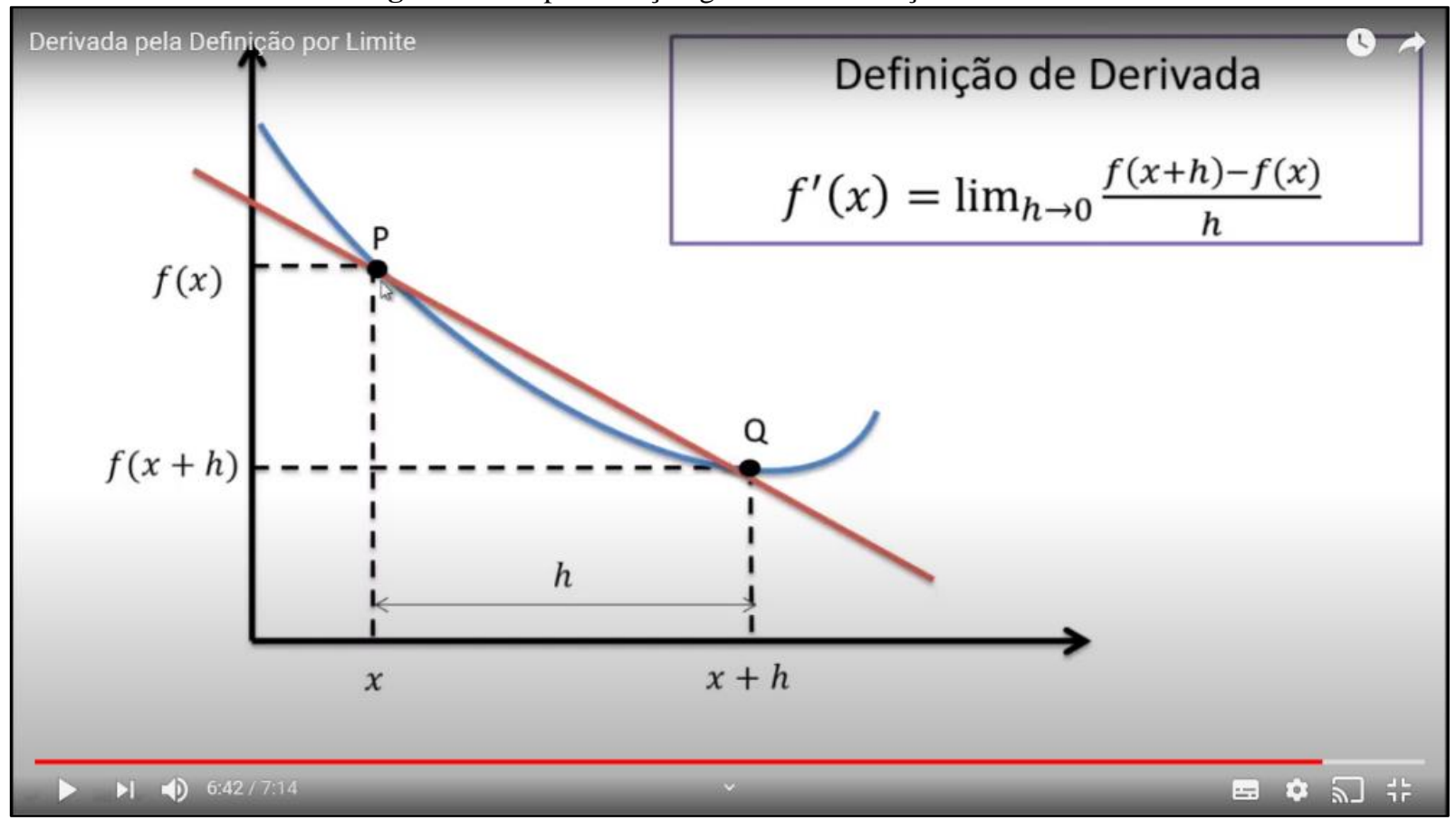

Fonte: Meira, F. [Canal Prof. Fabiano Meira]. Recuperado de https://youtu.be/D16AJQKdrhE

Finalizando o vídeo, é apresentada a representação gráfica de uma nova curva genérica, juntamente com uma reta que a intercepta em dois pontos (P e Q). Embora a representação mostre uma reta secante, sendo que a derivada se refere à inclinação de uma reta que tangencia a função em um determinado ponto, tal representação é conveniente, quando associada a uma indicação que a distância entre os pontos de intersecção tende a zero, indicando a reta secante se aproxima, cada vez mais de uma reta tangente. Nessa nova representação, a notação utilizada para nomear os elementos que compõem os pontos é a mesma utilizada na definição de derivada, de modo que possam se relacionadas, na busca de atribuição de significado a esses elementos.

\section{Considerações Finais}

Neste trabalho apresentou-se uma análise para discutir e refletir sobre potencialidades da análise de erros na identificação de dificuldades apresentadas por acadêmicos de Cálculo como caminho para a organização e planejamento favoráveis ao trabalho nessa área de conhecimento. Entende-se que a análise de erros cometidos por estudantes promova reflexões sobre ações que possam ser empregadas por docentes, a partir das dificuldades dos acadêmicos frente ao Cálculo, para reduzir os impactos negativos na sua aprendizagem. 
Com base nos dados obtidos a partir das resoluções analisadas, foi possível identificar diferentes tipos de erros relacionados à aplicação da definição de derivada para determinação da derivada primeira de uma função polinomial, os quais apontam para potenciais dificuldades de aprendizagem dos estudantes, tanto no âmbito conceitual quanto procedimental.

Dentre os erros observados, evidenciam-se erros relacionados tanto a aplicação de conhecimentos e procedimentos matemáticos que antecedem o próprio Cálculo (propriedade das potências e de produtos notáveis, uso de notação elementar, propriedade distributiva, simplificação de termos algébricos), mas que são essenciais ao estudá-lo, e erros relativo a atribuição de significado para as notações, particularmente no que se refere a limites. Esses erros refletem as dificuldades dos estudantes frente a utilização de instrumentos inerentes ao estudo do Cálculo e indicam, em dado entendimento, que possivelmente os acadêmicos não atribuem significado matemático considerado como adequado no contexto institucional, executando ações de cunho procedimental.

Entende-se que perceber e identificar os erros cometidos por acadêmicos permitam, de forma adequada e consoante as necessidades de um grupo de estudantes, tomar decisões para se utilizar recursos que busquem minimizar o acontecimento desses. No caso da investigação na qual esse trabalho está inserido, a análise de erros serviu como parâmetro para seleção de vídeos disponíveis no YouTube, a serem utilizados no contexto de uma monitoria online.

Destaca-se, porém, que a indicação de utilização de vídeos no contexto de um projeto de monitoria online não tem aqui caráter prescritivo servindo apenas como exemplo do tipo de trabalho que se defende. As possibilidades de caminhos metodológicos, estratégias e utilização de recursos são muitos e devem ser adotados a partir do conhecimento de um universo particular.

Por fim, destaca-se que, no contexto apresentado, a análise de erros mostrou-se como uma ferramenta efetiva no processo para o qual se destina e, em dada compreensão, configurase como um protocolo que pode guiar as ações docentes e auxiliar no processo de organização didática. Nesse intuito, entende-se que tenha condição eficaz como instrumento para qualificar o processo de ensino e aprendizagem não só do Cálculo, mas também em outros contextos e cenários matemáticos em que dificuldades de aprendizagem se apresentem. 


\section{Referências}

Anton, H. (2006). Cálculo: um novo horizonte - Volume 1. Porto Alegre, Brasil. Bookman.

Artigue, M. (1995). La enseñanza de los principios del cálculo: problemas epistemológicos, cognitivos y didácticos. Ingeniería Didática em Educación Matemática: Un esquema para la investigación em la enseñanza y el aprendizaje de las matemáticas. (pp. 97-140). Bogotá, Colômbia. Grupo Editorial Iberoamérica. Recuperado de http://funes.uniandes.edu.co/676/1/Artigueetal195.pdf

Barufi, M. C. B. (1999). A construção/negociação de significados no curso universitário inicial de Cálculo Diferencial e Integral. [Tese de Doutorado]. Universidade de São Paulo, Brasil. Recuperado de https://www.teses.usp.br/teses/disponiveis/48/48133/tde-06022004105356/publico/Tese.pdf

Bisognin, E., Fioreze, L. A., Cury, H. N. (2005). Análise de erros e proporcionalidade: uma experiência com alunos da graduação e pós-graduação. Vidya (Santa Maria). Volume (25), número (2), (pp. 31-40). https://periodicos.ufn.edu.br/index.php/VIDYA/article/view/392

Cury, H. N. (2008). Análise de erros: o que podemos aprender com as respostas dos estudantes. Belo Horizonte, Brasil. Autêntica.

Cury, H. N., Bisognin, E., Bisognin, V. (2009). A Análise de Erros como Metodologia de Investigação. Viana do Castelo-Portugal. ProfMat2009. (pp. 1-12). http://www.apm.pt/files/142359_CO_Cury_Bisognin_Bisognin_4a36c5d50a09a.pdf

Cury, H. N., Cassol, M. (2004). Análise de Erros em Cálculo: uma Pesquisa para Embasar Mudanças. Acta Scientiae. Volume (6), número (1), (pp. 27-36). Recuperado de http://www.periodicos.ulbra.br/index.php/acta/article/view/128

Del Puerto, S. M., Minnaard, C. L., Seminara, S. A. (2006,). Análisis de los errores: una valiosa fuente de información acerca del aprendizaje de las Matemáticas. Revista Iberoamericana de Educación. Volume (38), número (4,. (pp. 1-13). Recuperado de https://rieoei.org/RIE/article/view/2646

Movshovitz-Hadar, N., Zaslavsky, O., Inbar, S. (1987) An empirical classification model for erros in high school mathematics. Journal for Research in Mathematics Education. Volume (18), número (1), (pp. 3-14). Recuperado de https://www.jstor.org/stable/749532?seq=1\#page_scan_tab_contents

Oliveira, M. C. A. de., Raad, M. R. (2012). A existência de uma cultura escolar de reprovação no ensino de Cálculo. Boletim GEPEM. Volume (1), (pp. 125-137). Recuperado de http://www.ufjf.br/mestradoedumat/files/2011/09/Produto-educacional-Marcos-Raad.pdf

Pereira Filho, A. D., Kaiber, C. T., Lélis, F. R. de C. (2012). Categorização e Análise de Erros Cálculo Diferencial e Integral. Congresso Brasileiro de Educação em Engenharia (COBENGE). Recuperado de http://www.abenge.org.br/cobenge/arquivos/7/artigos/104513.pdf 
Reis, F. S. (2001, Fevereiro 23). A tensão entre rigor e intuição no ensino de Cálculo e Análise: A visão de professores-pesquisadores e autores de livros didáticos. [Tese de Doutorado]. Universidade Estadual de Campinas, Brasil. Recuperado de http://repositorio.unicamp.br/handle/REPOSIP/253451

Rezende, W. M. (2003, Junho 12). O Ensino de Cálculo: Dificuldades de Natureza Epistemológica. [Tese de Doutorado]. Universidade de São Paulo, Brasil. Recuperado de https://www.teses.usp.br/teses/disponiveis/48/48134/tde-27022014-121106/pt-br.php

Rico, L. (1995). Errores y dificultades en el aprendizaje de las matemáticas. Educación Matemática. (pp. 69-108). México. Grupo Editorial Iberoamérica S. A.

Scott Hood, P. A. de Q. (2018, Setembro). Cálculo Diferencial e Integral: uma proposta de monitoria online no Facebook. [Dissertação de Mestrado]. Universidade Luterana do Brasil, Brasil. $\quad$ Recuperado http://www.ppgecim.ulbra.br/teses/index.php/ppgecim/article/view/319

Scott Hood, P. A. de Q., Kaiber, C. T. (2017a). Mídias digitais e o estudo do Cálculo Diferencial e Integral. Congresso Internacional de Ensino de Matemática (CIEM). Recuperado de http://www.conferencias.ulbra.br/index.php/ciem/vii/paper/viewFile/8884/4350

Scott Hood, P. A. de Q., Kaiber, C. T. (2017b). Vídeos do YouTube como material de apoio no estudo de Cálculo Diferencial e Integral. Congresso Brasileiro de Educação em Engenharia (COBENGE).

Scott Hood, P. A. de Q., Kaiber, C. T. (2018a). Potencialidades do uso de vídeos online para estudo do Cálculo Diferencial e Integral. Encontro Gaúcho de Educação Matemática (EGEM).

Scott Hood, P. A. de Q., Kaiber, C. T., (2018b). Projeto Monitoria Online: o Facebook como potencial ambiente de aprendizagem. Revista de Matemática, Ensino e Cultura. Volume (13), número (28), (pp. 127-142). Recuperado de http://www.rematec.net.br/index.php/rematec/article/view/140 